\title{
A report of antibiotic restriction policy in Ghaem university hospital, Mashhad, Northea
}

\author{
Sepideh Hasanzadeh ${ }^{\mathrm{a}, \mathrm{b}}$, Ali Mehri ${ }^{\mathrm{c}}$, Mahya Manouchehri ${ }^{\mathrm{d}}$, Sara Ganjloo ${ }^{\mathrm{e}}$, \\ Mahin Sadat Shahabifar, Kiarash Ghazvini ${ }^{\mathrm{b}, *}$ \\ ${ }^{a}$ Antimicrobial Resistance Research Centre, Mashhad University of Medical Sciences, Mashhad, Iran \\ ${ }^{\mathrm{b}}$ Department of Microbiology and Virology, School of Medicine, Mashhad University of Medical Sciences, Mashhad, Iran \\ ${ }^{c}$ Student Research Committee, Faculty of Medicine, Mashhad University of Medical Sciences, Iran \\ ${ }^{\mathrm{d}}$ Ghaem University Hospital, Mashhad University of Medical Sciences, Mashhad, IR, Iran \\ ${ }^{\mathrm{e}}$ Department of Veterinary Medicine, Tehran University of Veterinary Science, Tehran, Iran \\ ${ }^{\mathrm{f}}$ Pharmacy of Ghaem Educational Hospital, Mashhad University of Medical Sciences, Iran
}

\section{A R T I C L E I N F O}

\section{Keywords:}

Antibiotic

Antibiotic usage

Restriction policy

\begin{abstract}
A B S T R A C T
Aim: The most serious problem in health care setting is over use and misuse antibiotics particularly in Iran. In 2017, some programs were implemented by the Iranian Ministry of Health (MOH) to controlling the antibacterial agent consumption in hospitals. This study evaluates the impact of implementation a restriction policy in Ghaem university hospital, which tries to limit the prescription of eight expensive antibiotics. Method: According to this policy the prescription of these antibiotics were only allowed by infectious disease specialists. The restriction policy of expensive antibiotics were initiated from April 21, 2018. We compared the consumption of these eight expensive antibiotics during 2 trimesters before and after the administration of this restriction policy. We also measured these drugs usage during the same period in previous year (April 21- July 22, 2017).

Results: The consumption was decreased $37.7 \%$ during trimester after the starting of restriction plan compare to similar period before it $(\mathrm{p}=0)$. The consumption had also declined compare to the same period in previous year.

Conclusions: This simple restriction policy was effective in decreasing the antibiotic usage in Ghaem university hospital.
\end{abstract}

\section{Introduction}

In 20 century, Antibiotics revolutionized the treatment of infections and enhanced the public health by reduction of morbidity and the mortality. ${ }^{1}$ The antibiotic consumption had coincided with the evolution of resistance among nosocomial and community-acquired infections. Antimicrobial resistance is a mounting concern for health system all around the world. ${ }^{2}$ based on evidence, there is strong correlation between antibiotic over use, hospital costs, reduction of sensitive gut flora and the emergence and dissemination of resistant bacteria strains. ${ }^{3,4}$ In American and European university hospital settings, antibiotics were prescribed in $60-90 \%$ of cases, more often there was no laboratory confirmation and no indication of antibiotic therapy in $40 \%$ of these cases. ${ }^{5,6}$

In Iran, over use of antibiotics has been reached critical levels demand on unnecessary prescription, therefore the average consumption of antibiotics is 2-4 times more than USA and Europe. Also the higher frequency of antibiotics misuse was found in surgical department compare with internal medicine unit, which have been utilized as prophylactic. $^{5,7}$ Misuse and over-prescription of antibiotics was spending a large portion of Iran's budget, which is treating the community health, increasing cost of patients and health-care setting. ${ }^{8,9}$

The antibiotic restriction policies can significantly reduce antibiotic consumption and health care cost. ${ }^{10,11}$ A systematic programs should been designed to optimize antibiotic use clinical outcome, provide effective antimicrobial therapy in order to limit the emergence of antimicrobial-resistant bacteria and related adverse effects. ${ }^{12}$ Approximately $60 \%$ of all American patients were prescribed an antibacterial drug during hospitalization, about $50 \%$ of this was unnecessary or otherwise inappropriate. In our country, this rate is higher more than 2

\footnotetext{
* Corresponding author. Department of Microbiology and virology, School of Medicine, Mashhad University of Medical Sciences, Ghaem hospital, Mashhad, Iran.

E-mail address: ghazvinik@mums.ac.ir (K. Ghazvini).
} 
to 4 times. ${ }^{6,12}$ Several strategies for antimicrobial stewardship have been suggested, such as educational efforts of healthcare providers, formulary restriction and review, antibiotic order forms, feedback activities, and approval requirement from an infection disease specialist for drug prescription. ${ }^{13}$

From 2018, the Iranian Ministry of Health made an effort to develop an antimicrobial restriction policy which reduce the antibiotic usage and economic cost. Based on this policy, administration of the eight expensive antibiotics were restricted without approval by an infectious disease specialist or internist (The number of letter: 31,991). The purpose of this study is how this policy could be effective on eight expensive antibiotics usage during three month before and after program, also compare to same period in previous year in Ghaem hospital of Mashhad.

\section{Material and method}

Our retrospective cross-sectional study was conducted in the Ghaem university hospital in all the wards (both medical and surgical, including pediatrics and obstetrics wards). This hospital is a third level hospital in northeast region of Iran. Approximately 43,000 patients were admitted annually, with a total capacity of 900 beds. This study was evaluated the effect of controlling the prescription of Carbapenems (Imipenem and Meropenem), Voriconazole, Vancomycin, Amphotericin B, Colistin, Linezolid, Ticoplanin and Caspofungin. This policy only allowed infectious specialists to prescribe these antibiotics. We analyzed the antibiotics consumption during 3 months before and after the administration of this policy. We also measured consumption during the same period in previous year. The antibiotic consumption is estimated in three ways: the total vial consumed, the antibiotics consumed in $\mathrm{mg}$ and the antibiotic consumption in $\mathrm{mg}$ toward the total hospitalized patients in each period. All statistical analyses were done using SPSS version 16.0. The antibiotics Anatomical Therapeutic Chemical (ATC) codes were extracted from WHO website.

\section{Result}

During trimester before the restriction plan, 10,148 patients were admitted in Ghaem hospital. The number of hospitalized patients were 12,543 during trimester after the policy started, which were 12,649 for previous year. About $80 \%$ of patients received at least one antibiotic dose. The demographic variables of studies were shown in Table 1 . The number of patients admitted in trimester after policy implementation was almost the same as last year. The number of patients decreased during the trimester before program, which could be due to the proximity of the New Year holiday.

Among these expensive antibiotics, meropenem was used more frequently in Ghaem hospital which accounted for $2094.68 \mathrm{mg} / \mathrm{pa}-$ tients, followed by vancomycin with $1699.31 \mathrm{mg} /$ patients of total consumption in these periods.

The total consumption was decreased from $26877760 \mathrm{mg}$ (2648.55 $\mathrm{mg} /$ patients) before the restriction started to $17630280 \mathrm{mg}$ (1405.65 $\mathrm{mg} /$ patients) during three month after it. Which means these antibiotics consumption were reduced about $34.4 \%$ although low hospitalization were occurred in Ghaem hospital $(\mathrm{p}=0)$ (Table 2). Furthermore, the antibiotic consumption in trimester after restriction policy had been

Table 1

Demographic variables of studies.

\begin{tabular}{|l|c|c|c|}
\hline \multicolumn{1}{|c}{ Variable } & After & Before & Previous year \\
\hline Hospital beds & 870 & 870 & 850 \\
\hline Number of wards & 43 & 43 & 41 \\
\hline Number of hospitalization patients & $\mathbf{1 2 5 4 2}$ & $\mathbf{1 0 1 4 8}$ & $\mathbf{1 2 6 4 9}$ \\
\hline Age (mean) & $\mathbf{4 2}$ & $\mathbf{4 0}$ & $\mathbf{4 5}$ \\
\hline Male (\%) & $\mathbf{5 6}$ & $\mathbf{5 5 . 2}$ & $\mathbf{5 7 . 5}$ \\
\hline Female (\%) & $\mathbf{4 4}$ & $\mathbf{4 4 . 8}$ & $\mathbf{4 2 . 5}$ \\
\hline
\end{tabular}

Table 2

Antibiotics consumption before and after restriction Plan.

\begin{tabular}{|l|c|c|c|c|c|c|c|}
\hline \multirow{2}{*}{ Drug } & ATC code & \multicolumn{3}{|c|}{ Total Antibiotics consumed (mg) } & \multicolumn{3}{c|}{$\begin{array}{c}\text { Consumption/patients } \\
\text { (mg/patient) }\end{array}$} \\
\cline { 3 - 10 } & & Last year & $\begin{array}{c}\text { before } \\
\text { restriction } \\
\text { plan }\end{array}$ & $\begin{array}{c}\text { after } \\
\text { restriction } \\
\text { plan }\end{array}$ & Last year & $\begin{array}{c}\text { before } \\
\text { restriction } \\
\text { plan }\end{array}$ & $\begin{array}{c}\text { after } \\
\text { restriction } \\
\text { plan }\end{array}$ \\
\hline Imipenem 500 & J01DH51 & $2,307,500$ & $2,746,500$ & $1,627,500$ & 182.42 & 270.64 & 129.76 \\
\hline Meropenem & J01DH02 & $14,690,000$ & $16,612,500$ & $10,359,500$ & 1161.35 & 1637.02 & 825.98 \\
\hline Colistin & J01XB01 & 114,640 & 94,960 & 179,880 & 9.06 & 9.35 & 14.34 \\
\hline Vancomycin 500 & J01XA01 & $6,941,500$ & $7,363,000$ & $5,433,000$ & 548.77 & 725.56 & 433.18 \\
\hline Caspofangin 50 & J02AX04 & 3,550 & 50 & 4,100 & 0.28 & 0.0049 & 0.32 \\
\hline Teicoplanin 400 & J01XA02 & 7,200 & 46,400 & 22,800 & 0.57 & 4.57 & 1.80 \\
\hline Amphotericin B 50 & J02AA01 & 0 & 14,350 & 3,500 & 0 & 1.41 & 0.27 \\
\hline Total & & $\mathbf{2 4 , 0 6 4 , 3 9 0}$ & $\mathbf{2 6 , 8 7 7 , 7 6 0}$ & $\mathbf{1 7 , 6 3 0 , 2 8 0}$ & $\mathbf{1 9 0 2 . 4 5}$ & $\mathbf{2 6 4 8 . 5 5}$ & $\mathbf{1 4 0 5 . 6 5}$ \\
\hline
\end{tabular}

reduced about $24,064,390 \mathrm{mg}$ (1902.45 $\mathrm{mg} /$ patients) comparing to the same period in the previous year, $(26.1 \%)$. The most prominent reduction of antibiotics usage was observed for imipenem, which had been decreased from $182.42 \mathrm{mg}$ /patient to $129.76 \mathrm{mg}$ /patient during previous year compare to restriction plan started. In the next step, the consumption of meropenem were reduced from $1161.35 \mathrm{mg} /$ patient to $825.98 \mathrm{mg} /$ patient and, reduction in vancomycine usage were reported from $548.77 \mathrm{mg} /$ patient to $433.18 \mathrm{mg}$ /patient during previous year compare to restriction plan started. Unfortunately, voriconazole was not available for prescriptions during our study.

\section{Discussion}

Our local program have emphasized on monitoring compliance with antibiotic prescriptions and reduced consumption which would optimize the quality of treatment. Our results indicated that most of these expensive antibiotic usage decreased during this restriction period following by approval specialist. Assessing the hospital antibiotics usage during 2 trimesters before and after implantation policy indicated that antibiotics consumption has decreased by $34.4 \%$ and was $28.1 \%$ compared to the previous year. Contrary to the above results, some of these antibiotics consumption such as caspofangin, colistin have been increased in three month after administration compare with same period in last year, which can be attributed to lack of access due to some sanctions in previous year. The prescribing restriction by infectious disease specialist or internist is provided a fundamental strategy which improve antibiotics consumption. Many Iranian studies have shown the effectiveness of these measures. ${ }^{7,13,14}$

In Kerman, the use of carbapenems and vancomycin were restricted based on the directive of Health Ministry. This investigation showed the consumption of meropenem and vancomycin were decreased from $72.3 \%$ to $49 \%$ and $60.9 \%-37.7 \%$, respectively. However, imipeneme consumption was increased from $5 \%$ to $8 \%$. The same restriction policy were implemented in Emam Ali hospital of Karaj which narrowed eight expensive antibiotics including colistin, imipenem, meropenem, linezolide, vancomycin, amphotericin $\mathrm{B}$, voriconazole, teicoplanin and caspofangin. The consumption of colistin, caspofangin and amphotericin have been reported to decrease about $63.5 \%$ and $15 \%$ for imipenem, meropenem and linezolide. The consumption of teicoplanin and voriconazole have increased. In our hospital, meropenem, imipenem and vancomycin were consumed more frequently before administration these policy, which has dramatically decreased after it. The usage of antibiotics highlighted in this policy were decreased while other antibiotics have been reported to increase especially clindamycin which not monitored by this plan.

The measurement of antibiotics consumption in hospitals could estimate and improve overuse of antibiotics and treatment cost consequently. ${ }^{15-17}$ In conclusion, this study showed that the specialist approval and restriction policy reduce the antibiotics consumption effectively. The improvement of antibiotics usage is a major challenge. Therefore it requires education and collaboration of all medical team 
members which can consist a fundamental strategy to increase the efficacy of antibiotics usage, which probably decrease costs and antibiotics resistance. According to recent study, the implementation of long-stanging restriction policy for all antibiotics is required in every health care system. The effective implementation of these policies were attended by insurances and health ministry.

\section{Funding}

The authors declare that no funding was received to prepare this review.

Availability of data and materials. Data was obtained from the Mashhad University of Medical Sciences Ghaem hospital.

\section{Declaration of competing interest}

The authors declare that they have no competing interests.

\section{Acknowledgements}

Not applicable.

\section{References}

1. Hulscher ME, van der Meer JW, Grol RP. Antibiotic use: how to improve it? Int J Med Microbio. 2010;300(6):351-356.

2. Safdari R, Ghazi Saeedi M, Masoumi-Asl H, et al. National minimum data set for antimicrobial resistance management: toward global surveillance system. Iran J Med Sci. 2018;43(5):494-505.

3. Fair RJ, Tor Y. Antibiotics and bacterial resistance in the 21st century. Perspect Med
Chem. 2014;6:S14459 PMC

4. Revelas A. Healthcare-associated infections: a public health problem. Niger Med J: $J$ Niegeria Med Assoc. 2012;53(2):59.

5. Gendel I, Azzam ZS, Braun E, Levy Y, Krivoy N. Antibiotic utilization prevalence: prospective comparison between two medical departments in a tertiary care university hospital. Pharmacoepidemiol Drug Saf. 2004;13(10):735-739.

6. Mazzeo F, Capuano A, Motola G, et al. Antibiotic use in an Italian university hospital $J$ Chemother. 2002;14(4):332-335.

7. Hatam N, Askarian M, Moravveji AR, Assadian O. Economic burden of inappropriate antibiotic use for prophylactic purpose in Shiraz, Iran. Iran Red Crescent Med J. 2011;13(4):234.

8. Benko R, Matuz M, Doró P, et al. Antibiotic consumption between 1996 and 2003: national survey and international comparison. Orv Hetil. 2006;147(26):1215-1222.

9. Wettermark B, Elseviers M, Almarsdóttir AB, et al. Introduction to drug utilization research. Drug Util Rev: Methods Appl. 2016:1-12.

10. Tunger O, Karakaya Y, Cetin CB, Dinc G, Borand H. Rational antibiotic use. J Infect Dev. Ctries. 2009;3(2) 088-93.

11. Srishyla M, Nagarani M, Venkataraman B. Drug utilization of antimicrobials in the in-patient setting of a tertiary hospital. Indian J Pharmacol. 1994;26(4):282

12. Barlam TF, Cosgrove SE, Abbo LM, et al. Implementing an antibiotic stewardship program: guidelines by the infectious diseases society of America and the society for healthcare epidemiology of America. Clin Infect Dis. 2016;62(10):e51-e77.

13. Vahidi G, Mohammadi M, Shojaei L, Ramezani M, Jafari S, Khalili H. Antibiotic stewardship program in intensive care unit: first report from Iran. Int J Crit Illness Inj Sci. 2018;8(2):83.

14. Adeli O, Moghaddam NM, Farahani RH, Jame SZB. Antibiotics use patterns in in tensive care units of five hospitals in Tehran during 2011-2012. J Arch Mil Med. 2015;3(3).

15. Sutherland T, Beloff J, Lightowler M, et al. Description of a multidisciplinary initiative to improve SCIP measures related to pre-operative antibiotic prophylaxis compliance: a single-center success story. Patient Saf Surg. 2014;8(1):37.

16. Dimopoulou A, Kourlaba G, Psarris A, Coffin S, Spoulou V, Zaoutis T. Perioperative antimicrobial prophylaxis in pediatric patients in Greece: compliance with guidelines and impact of an educational intervention. J Pediatr Surg. 2016;51(8):1307-1311.

17. Garcell HG, Arias AV, Sandoval CP, Gamboa MEV, Sado AB, Serrano RNA. Impact of a focused antimicrobial stewardship program in adherence to antibiotic prophylaxis and antimicrobial consumption in appendectomies. $J$ Infect Public Health. 2017;10(4):415-420. 